\title{
Embedding Embryos for High-Resolution Episcopic Microscopy (HREM)
}

\author{
Timothy J. Mohun and Wolfgang J. Weninger
}

Episcopic fluorescence image capturing (EFIC) and high-resolution episcopic microscopy (HREM) are related techniques that are used to generate digital volume data and create three-dimensional (3D) images. Both techniques require specimens that are embedded in an appropriate medium, and images are captured from successive sections before removal from the embedded tissue block. EFIC detects autofluorescence emitted from the embedded tissue, whereas HREM requires the tissue to be stained with a fluorescent dye such as eosin. Different procedures are therefore necessary for embedding tissue for EFIC or HREM imaging. For HREM, the choice of fixative appears to be of little consequence. If gene expression patterns are to be visualized in addition to tissue architecture, whole-mount staining for gene expression patterns using the 4-nitro blue tetrazolium chloride (NBT)/5-bromo-4-chloro-3indolyl phosphate (BCIP) or LacZ detection system must be performed before embedding of samples. This protocol describes the procedure for embedding E11.5 mouse embryos for HREM imaging. Processing times should be adapted for the size and nature of other specimens.

\section{MATERIALS}

It is essential that you consult the appropriate Material Safety Data Sheets and your institution's Environmental Health and Safety Office for proper handling of equipment and hazardous materials used in this protocol.

Reagents

\section{Eosin B (Sigma-Aldrich)}

JB-4 resin embedding kit (Polysciences, Inc.)

Prepare both infiltration and embedding solutions as specified, except add $0.275 \mathrm{~g}$ of eosin B/100 $\mathrm{mL}$ and $0.055 \mathrm{~g}$ of acridine orange (Sigma-Aldrich) $/ 100 \mathrm{~mL}$ to both.

Methanol (or ethanol) (100\% and a series of 70\%, 80\%, 85\%, 90\%, 95\% in $\mathrm{H}_{2} \mathrm{O}$ )

Specimens of interest, fixed

Bouin's fixative or $4 \%$ buffered paraformaldehyde both provide good retention of tissue architecture and minimize shrinkage during sample dehydration.

Equipment

Block holder

Box, airtight, flushed with nitrogen, to minimize inhibition of polymerization of the embedding solution by oxygen (see Step 8)

A layer of paraffin oil or paraffin wax may be used as an alternative.

Dissecting microscope with an illuminated base

Adapted from Imaging in Developmental Biology (ed. Sharpe and Wong). CSHL Press, Cold Spring Harbor, NY, USA, 2011.

(C) 2012 Cold Spring Harbor Laboratory Press

Cite this article as Cold Spring Harb Protoc; 2012; doi:10.1101/pdb.prot069583 
Embedding molds

Use polyethylene molding cup trays $(6 \times 8 \times 5-m m$ or $13 \times 19 \times 5$-mm; Polysciences, Inc.) for small samples and custom Teflon molds for larger samples.

Forceps or a blunt needle (for handling specimens)

Petri dishes (plastic)

Rocker or rotator

Spoon, small (for handling specimens)

1. Rinse fixed specimens in tap water for several hours.

2. Dehydrate the samples by using a graded methanol or ethanol series at room temperature and constant gentle rocking or rotation.

For E11.5 embryos, it is sufficient to incubate for 30-60 min at each stage of a series of $70 \%, 80 \%, 85 \%$, $90 \%, 95 \%$, and $100 \%$ methanol or ethanol. For older mouse embryos up to 16.5 days postcoitum (dpc), increase the incubation times by 15-30 min per day of age >11.5 dpc. For larger samples (e.g., E14.5 and older), inclusion of eosin in the methanol dehydration series may help tissue staining.

3. Infiltrate as follows, keeping the samples gently rocking or rotating throughout:

i. Transfer the embryos to JB-4 infiltration solution:100\% methanol (50:50) and incubate for at least $1 \mathrm{~h}$ at $4^{\circ} \mathrm{C}$.

ii. Transfer to $100 \%$ JB-4 infiltration solution and incubate for a minimum of $3-4 \mathrm{~h}$ (preferably overnight) at $4^{\circ} \mathrm{C}$. Change to fresh $100 \%$ JB-4 infiltration solution several times during the incubation.

4. Prepare the JB-4 embedding solution immediately before embedding and keep it at $4^{\circ} \mathrm{C}$.

5. Pour cooled embedding solution into the embedding molds and add the samples. See Troubleshooting.

6. As soon as the viscosity of the embedding solution begins to increase (usually within 15-20 min), align the specimen with forceps or a blunt needle.

Specimens can most easily be observed using a dissecting microscope with an illuminated base.

See Troubleshooting.

7. As soon as the embedding solution starts to thicken, place a block holder on top of the embedding mold and pour embedding solution into the mold until the mold with the block holder is filled with embedding solution.

8. Minimize inhibition of polymerization by oxygen using one of the following methods:

i. Place samples in an airtight box flushed with nitrogen.

ii. Cover the embedding solution with a layer of paraffin oil or paraffin wax.

iii. Place a second molding cup tray upside down on top of the one holding the specimens and seal with tape.

9. Allow the JB-4 plastic resin to polymerize completely for $12-24 \mathrm{~h}$ at $4^{\circ} \mathrm{C}$.

10. Remove the blocks from the trays and allow them to dry for $1 \mathrm{~d}$ at $25^{\circ} \mathrm{C}-37^{\circ} \mathrm{C}$. Store the blocks at either $4^{\circ} \mathrm{C}$ or at room temperature before use.

Avoid humid conditions because this can cause blocks to soften.

For large blocks, attachment to the block holder via JB-4 resin may be inadequate and the block may break from the holder during sectioning. To avoid this, it can be helpful to cut the block away from the existing block holder and reattach it to a fresh holder using contact adhesive.

See Troubleshooting. 
Problem (Step 5): The JB-4 embedding solution starts hardening before it is poured into the molding cup trays because embedding is performed at room temperature.

Solution: Make a "cooling bath" (with ice cubes) in a deep Petri dish. Put a stirrer into a flask with the embedding solution, put this flask in to the cooling bath, and put the cooling bath onto a magnetic stirrer. Pipette the embedding solution quickly and carefully into the molds.

Problem (Step 6): The irregular shape of the specimen makes proper alignment impossible.

Solution: Embed the specimen in agar before plastic resin embedding.

Problem (Step 10): The block has not properly hardened after storage in the refrigerator.

Solution: If blocks appear soft, they can be hardened by baking at $80^{\circ} \mathrm{C}-90^{\circ} \mathrm{C}$. Blocks will soften dramatically at this temperature, but harden as they cool to room temperature. Depending on the size of the block and its softness, baking may be needed from overnight up to several days.

\section{RELATED INFORMATION}

A procedure to embed embryos for EFIC is described in Embedding Embryos for Episcopic Fluorescence Image Capturing (EFIC) (Mohun and Weninger 2012a). Digital data processing, visualization, and archiving for both EFIC and HREM is described in Generation of Volume Data by Episcopic Three-Dimensional Imaging of Embryos (Mohun and Weninger 2012b). For an introduction to EFIC and HREM, see Episcopic Three-Dimensional Imaging of Embryos (Mohun and Weninger 2012c).

\section{ACKNOWLEDGMENTS}

We thank S.H. Geyer, M.F. Bennett, and L. Dunlevy.

\section{REFERENCES}

Mohun TJ, Weninger WJ. 2012a. Embedding embryos for episcopic fluorescence image capturing (EFIC). Cold Spring Harb Protoc doi: 10.1101/ pdb.prot069575.

Mohun TJ, Weninger WJ. 2012b. Generation of volume data by episcopic three-dimensional imaging of embryos. Cold Spring Harb Protoc doi: $10.1101 /$ pdb.prot069591.
Mohun TJ, Weninger WJ. 2012c. Episcopic three-dimensional imaging of embryos. Cold Spring Harb Protoc doi: 10.1101/pdb.top069567. 


\section{Embedding Embryos for High-Resolution Episcopic Microscopy (HREM)}

Timothy J. Mohun and Wolfgang J. Weninger

Cold Spring Harb Protoc; doi: 10.1101/pdb.prot069583

\begin{tabular}{|c|c|}
\hline $\begin{array}{r}\text { Email Alerting } \\
\text { Service }\end{array}$ & Receive free email alerts when new articles cite this article - click here. \\
\hline $\begin{array}{r}\text { Subject } \\
\text { Categories }\end{array}$ & $\begin{array}{l}\text { Browse articles on similar topics from Cold Spring Harbor Protocols. } \\
\text { Developmental Biology ( } 728 \text { articles) } \\
\text { Fluorescence (517 articles) } \\
\text { Imaging Development ( } 255 \text { articles) } \\
\text { Mouse (437 articles) }\end{array}$ \\
\hline
\end{tabular}

